\title{
Analysis of thermal environment of Existing Residential Building Envelope Energy-saving in ECOTECT simulation
}

\author{
Zhang Suxian, Feng Bo
}

(School of Management ,Xi'an Univ. of Arch. \&Tech., Xi'an710055,china)

Keywords: Envelope; energy saving; ECOTECT energy simulation; temperature distribution; thermal comfort

\begin{abstract}
Currently existing residential buildings energy-saving are include two ways: reform of building envelope and reform of building heat metering system. The study of building envelope energy-saving technical measures includes: wall insulation, window glazing, roofing insulation, However energy-saving for reform of building envelope can reduce energy consumption, but also have a significant impact of the indoors thermal environment. In this paper, ECOTECT simulation different ways of reform envelope in Xi'an Residential Building to analysis their thermal environment. in-depth analysis of different programs in energy consumption, incomfortable, envelope too hot, the temperature distribution and thermal comfort circumstances, Choose the best program to target the beset thermal comfortable. To provide the basis for existing residential buildings energy-saving Scheme.

Renovation of existing buildings abroad progress soon, after the energy crisis of 1973 began the transformation of existing buildings in developed countries, Northern Europe, Central Europe in the mid-20th century completed the energy-saving, Western Europe, the United States continues existing buildings for energy saving ${ }^{[1]}$.

Alaa, Moncef research on the Structure Optimization Saudi Arabia Residential Building Envelope junction,Including wall insulation, roof insulation, window area, window glass, window shading, and thermal mass, etc. ${ }^{[2]}$. Nopparat, SomsakStudy install blinds on indoor thermal comfort $^{[3]}$.Chinese scholars Tang Tian-fen, Wang Min-rong the status of residential building envelope Jiangmen both conducted a survey,Analysis of the existing residential Jiangmen City building envelope thermal performance and the use of state and make recommendations for energy-saving building envelope ${ }^{[4]}$.Zhang sai, Wan Yuan-lin studied in cold areas of the city for residential energy-saving renovation of existing buildings, From the construction of the outer window "facades" "roof" of heating and other aspects related to energy-saving technology ${ }^{[5]}$.Yang Qian, Yang Liu, Liu Jia-ping for summer residence in Xi'an indoor thermal comfort research,Concluded at the same time improve indoor thermal comfort, it can significantly reduce the energy consumption of construction equipment ${ }^{[6]}$.Bai Lu-jian, Song Bing, Yang Liu study Xi'an building indoor hot spring comfortable living human,Analyze the thermal comfort conditions ${ }^{[7]}$.

Thermal comfort factor to consider based on the previous article on the envelope energy-saving program studies, ECOTECT energy simulation software using thermal environment of a residential building envelope in Xi'an different energy saving programs to simulate,Depth analysis of the energy consumption of different energy-saving solutions, not comfort and thermal comfort conditions, thermal comfort as a precondition to choose the best energy-saving energy-saving program for the purpose of the goal.
\end{abstract}

\section{Residential Selection}

Selected is housed in a representative house, is nearly five years in the form of general residential area of Xi'an.The residence is located in the eastern outskirts of Xi'an, Shaanxi Province and Design Institute of Modern Architecture residential building No.3.1998 design, completed in 2000.Brick structure, seven layers, a planar shape, a total of four units.Length $75.78 \mathrm{~m}$, width $1 \mathrm{l} .64 \mathrm{~m}$, general-storey $2.8 \mathrm{~m}$, top storey $2.9 \mathrm{~m}$, total height of $19.7 \mathrm{~m} .1$ to 5 layers south, north to the external walls of $370 \mathrm{~mm}$ thick, the rest of the wall is $240 \mathrm{~mm}$ thick.Residential north-south layout, 
stairwells without heating.Balcony enclosed with steel windows.Table 1 Specific structural configuration.

Tab.1 Residential basic parameters and envelope structure

\begin{tabular}{|c|c|c|}
\hline \multirow[b]{3}{*}{$\begin{array}{l}\text { Envelope } \\
\text { constructi } \\
\text { on }\end{array}$} & Facades & $\begin{array}{l}\text { 20mm Lime mortar stucco } \\
\text { 370mm KPI Bearing cellular(240mm KPI Bearing cellular) } \\
\text { 20mm Cement Stucco }\end{array}$ \\
\hline & $\begin{array}{l}\text { Outside } \\
\text { windows }\end{array}$ & Single glass steel windows \\
\hline & Roof & 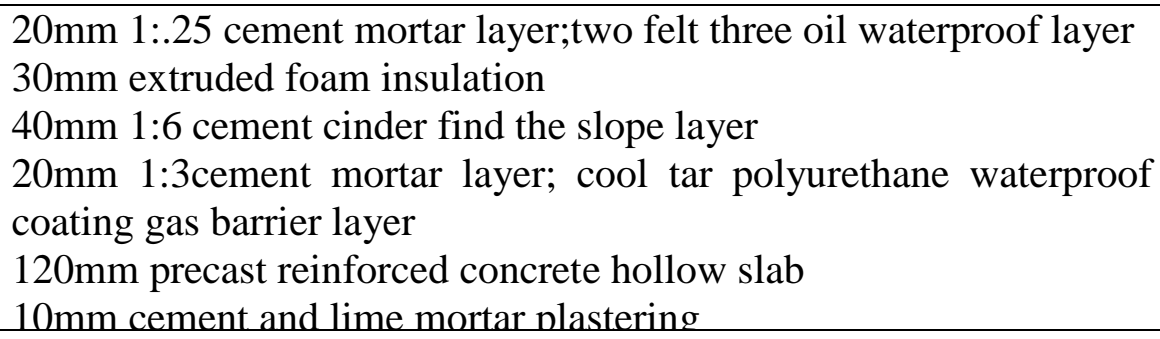 \\
\hline
\end{tabular}

\section{Choose energy-saving programs}

According to Xi'an envelope first energy efficiency standards, There are 6 kinds of roof structure practice, 5 kinds of exterior wall structure practice, there are three kinds of windows. combined with the practice of selecting four kinds of rehabilitation programs,As shown in Table 2.

Tab.2 Energy-saving program

\begin{tabular}{|c|c|c|c|}
\hline B-Facades renovation & C-Facades renovation & $\begin{array}{l}\text { D-window } \\
\text { renovation }\end{array}$ & $\begin{array}{l}\text { E-window } \\
\text { renovation }\end{array}$ \\
\hline 20mm cement mortar & 3mm polymer mortar & \multirow{4}{*}{$\begin{array}{l}\text { Single-frame } \\
\text { double } \\
\text { glass plastic } \\
\text { windows }\end{array}$} & \multirow{4}{*}{$\begin{array}{l}\text { Air glass steel } \\
\text { windows }\end{array}$} \\
\hline 50mm hydrophobic & $25 \mathrm{~mm}$ extruded foam & & \\
\hline $\begin{array}{l}\text { perlite board } \\
240 \mathrm{mmKP1}\end{array}$ & $\begin{array}{l}3 \mathrm{~mm} \text { polymer mortar } \\
20 \mathrm{~mm} \text { cement mortar }\end{array}$ & & \\
\hline cellular & 240mmKP1 bearing & & \\
\hline
\end{tabular}

\section{ECOTECT Energy Simulation}

Based on residential buildings envelope construction practices given material. Building models in the ECOTECT software,Five kinds of renovation programs envelope model, the model will look the same,As shown in Figure 1.

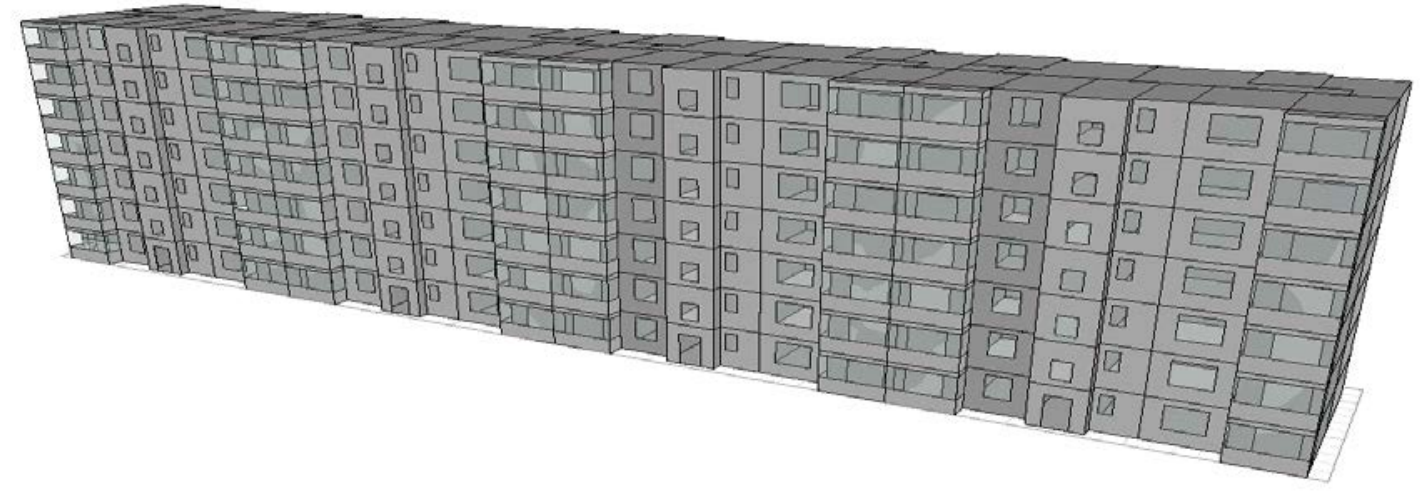

Fig1 Residential building energy simulation model

5 kinds of program models were used to build ECOTECT software simulation analysis on thermal environment, A program is the original envelope for the building envelope as shown in Table 1.According to Xi'an climate data,Analysis of five kinds of programs in energy consumption, 
not comfort and thermal comfort situation,Finally, to select the optimal thermal comfort energy-saving solutions for the goal.

3.1Analysis of the monthly energy consumption of different options

Ecotect Analysis to simulate and analyze the overall monthly energy consumption of the building heating and air conditioning of each area,Monthly energy analysis results shown in Figure 2.

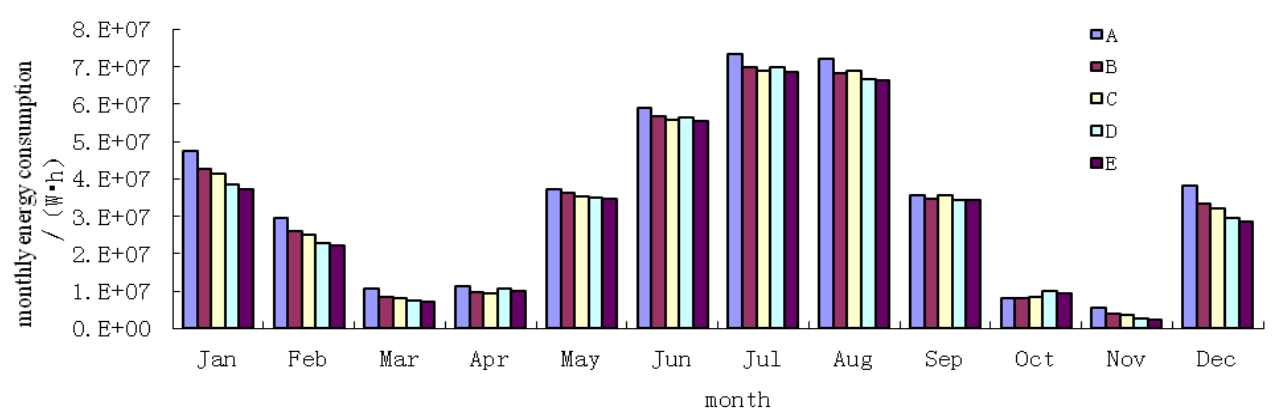

Fig2 Programs monthly energy consumption

From November to March and May of five programs in energy consumption was a significant downward trend in the ladder, but in April D programs and E program energy consumption is higher than B and C programs, which shows little outside the window U-value heat good insulation properties low capacity in climate from low to high temperatures over a period of no help to reduce energy consumption.

June to September, B, C, D, E four scenarios of energy consumption does not reduce the amount of November to March so obvious, which shows good insulation properties envelope is useful in winter, but in summer there are certain disadvantage.

3.2 Different scenarios analyzed monthly discomfort

Ecotect Analysis can be calculated monthly based on the degree of discomfort associated comfort temperature.

Simulation results shown in Figure 3.

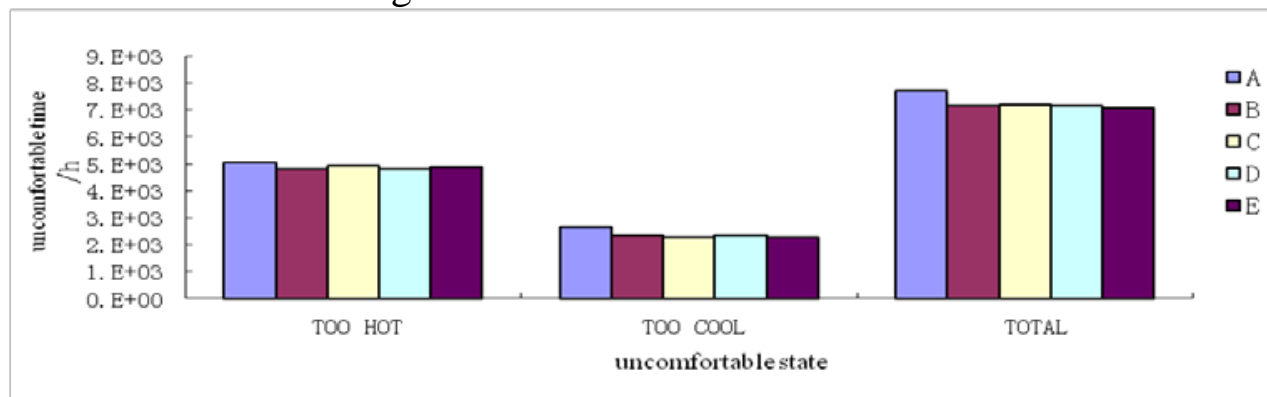

Fig3 Programs monthly discomfort times

Cold B and D programs discomfort similar time, hot E and C programs discomfort similar time, these four rehabilitation programs total time less discomfort, discomfort A program time most.This result is consistent with the results of monthly energy consumption. Also described envelope insulation performance good in the winter is beneficial, but in the summer there are some disadvantages.

3.3 Comfort spatial analysis of different programs

Comfort Ecotect Analysis Analysis of the regional management model based on the relative humidity settings dialog box, five indicators clothing, wind speed and calculated indoor dry bulb temperature, mean radiant temperature PMV come and PPD, and the results are presented on the web lattice. The results shown in Table 3. 
Tab.3 Thermal comfort simulation results of the program

\begin{tabular}{lccccc}
\hline $\begin{array}{l}\text { Thermal comfort } \\
\text { parameters }\end{array}$ & $\mathrm{A}$ & $\mathrm{B}$ & $\mathrm{C}$ & $\mathrm{D}$ & $\mathrm{E}$ \\
\hline $\begin{array}{l}\text { PMVtotal range of } \\
\text { equivalence }\end{array}$ & $3.5 \sim 23$. & $0.2 \sim 20.2$ & $5.0 \sim 15.0$ & $-5.5 \sim 14.5$ & $-5.3 \sim 14.7$ \\
PMV average value & 5 & & & & \\
PPD total range & 5.79 & 2.89 & 3.0 & 3.14 & 3.23 \\
PPD average value & $99 \sim 100$ & $6 \sim 96$ & $6 \sim 96$ & $5 \sim 95$ & $6 \sim 96$ \\
\hline
\end{tabular}

International Standards Organization (ISO) standards of comfort (ISO 7730) Recommended indoor environmental thermal comfort standards: $-0.5<\mathrm{PMV}<0.5$, Chinese acceptable thermal environment of comfort PMV:-1.0 $<\mathrm{PMV}<1.0$, Corresponding PPD:PPD $<26 \%{ }^{[8]}$ 。

$\mathrm{B}, \mathrm{C}, \mathrm{D}, \mathrm{E}$ four kinds of rehabilitation programs in energy consumption, not comfort and thermal comfort three aspects have a significant effect of improving thermal comfort as the main factor in choosing B solution is optimal.

\section{Conclusions and discussion}

\subsection{Conclusion}

By the Shaanxi Provincial Institute of Contemporary Architecture Design No.3 residential building envelope energy-saving simulation analysis of different scenarios can draw the following 3 conclusions.

1. Transform facades and external window $U$ value reduced by retaining structure, reduce the heat transfer capability envelope, increasing the insulation performance of the building envelope, thus effectively reducing the energy consumption of buildings and increase indoor comfort temperature time, improve indoor thermal comfort.

2. The total energy consumption and monthly energy consumption simulation results reflect the transformation of the outer window has obvious advantages over the facades transformation. Description envelope U-value type of transformation of the transformation of the building envelope to reduce energy consumption for buildings greater impact compared to the transformation of the outer window is more conducive to reducing energy consumption.

3. Thermal comfort simulation results reflect the external walls of the transformation has obvious advantages than the outer window transformation. U-value change thermal comfort and performance is the best program of a minimum of $\mathrm{B}$, which shows both the residential envelope for energy saving is not the U-value, the better the smaller the thermal comfort.

4.2 The lack of research

Choose energy-saving thermal comfort solutions existing residential buildings is the optimum goal, only a software simulation of a lack of comparative analysis and practical engineering, after research can contact real envelope energy-saving projects for analysis.

\section{Reference}

[1] Tian jiao zhang, Liang Fang. Energy-saving Renovation of Existing Residential Buildings in Wuhan[J]. Architectural Practice,2012(10): 44 47.

[2] Alaa Alaidroos, Moncef Krarti.Optimal design of residential building envelope systems in the Kingdom of Saudi Arabia[J].Energy and Buildings 2015 (86) 104 117.

[3] Nopparat Khamporn, Somsak Chaiyapinunt.Effect of installing a venetian blind to a glass window on human thermal comfort[J].Building and Environment, 2014 (82) 713 725.

[4] Tian fen Tang, Min rong Wang. A study of building envelope of and energy saving measures for existing residential buildings in Jiang men[J].Journal of Wuyi university(Natural science edition) ,2014,28(2)69 73. 
[5] Sai Zhang, Yuan lin Wan, Ping bo Wang, Mi na Cao. Study on existing residential building energy-saving reconstruction in cold region[J]. Construction Technology,2013,(42):488 490.

[6] Qian Yang, Liu Yang, Jia ping Liu. Field Study on Thermal Comfort in Summer of Xi'an Urban Residence Buildings[J], Refrigeration and Air Conditioning,2011,25(1):49 52.

[7] Lu jian Bai, Bing Song, Liu Yang. Field study on occupant thermal com fort of residential buildings in Xi'an in Spring[J],Building energy efficiency,2014(11):68 71.

[8] Jing feng Xu.Discussion on the application range of the PMV equation[J].Journal of Chongqing Jianzhu university,2005,27(3):43 44. 